\title{
Congenital anomalies in neonates in Fayoum Governorate, Egypt
}

Heba ElAwady, ${ }^{1}$ Alkasem AlGameel, ${ }^{1}$ Tamer Ragab ${ }^{2}$ and Nasser Hassan ${ }^{3}$

${ }^{1}$ Department of Pediatrics, Faculty of Medicine, Fayoum University Hospitals, Fayoum University, Fayoum, Egypt (Correspondence to: H. ElAwady: Hebawady@yahoo.com). ²Cardiology Department, Fayoum University, Fayoum, Egypt. ${ }^{3}$ Pediatrics Department , Fayoum General Hospital, Fayoum, Egypt

\begin{abstract}
Background: The worldwide incidence of congenital anomalies (CAs) is estimated at 3-7\%, but actual numbers vary widely among countries. Birth defects are the most common causes of infantile mortality, accounting for $\sim 25 \%$ of all neonatal deaths.
\end{abstract}

Aims: To determine the prevalence of congenital anomalies in neonates in Fayoum Governorate; to classify malformations; and to clarify the association between congenital anomalies and possible risk factors.

Methods: A cross-sectional study was conducted on 1000 infants in the neonatal intensive care unit and outpatient clinics of Fayoum University Hospital and Fayoum General Hospital during August 2017 to April 2018. Detailed history, clinical examination and relevant investigations were performed.

Results: The prevalence of CAs was 7.4\%. Major malformations accounted for $78.4 \%$ and minor malformations $21.6 \%$. The most common CAs involved the cardiovascular system (32.4\%), followed by musculoskeletal anomalies (18.9\%), chromosomal anomalies (10.8\%), anomalies of the central nervous system (9.5\%), gastrointestinal tract (6.8\%), genital system (5.4\%), eyes, head and neck (5.4\%), respiratory system (4.1\%), multisystems ( 2 or more) $(4.1 \%)$, and renal and urinary systems ( $2.7 \%)$. $82.4 \%$ of cases were from rural areas, $62.1 \%$ were male, $36.5 \%$ were female and $1.4 \%$ were ambiguous. $85.1 \%$ of neonates with malformations were full term.

Conclusion: Cardiovascular, musculoskeletal and chromosomal anomalies were the most common CAs in our study. Positive consanguinity, poor attendance at antenatal clinics, rural residence and multiparty were the most common risk factors associated with CAs.

Keywords: birth defects, congenital anomalies, Egypt, prevalence, risk factors.

Citation: ElAwady H; AlGameel A; Ragab T; Hassan N. Congenital anomalies in neonates in Fayoum Governorate, Egypt East Mediterr Health J. 2021;27(8):790-797. https://doi.org/10.26719/emhj.21.033

Received: 04/02/20; accepted: 24/01/21

Copyright (C) World Health Organization (WHO) 2021. Open Access. Some rights reserved. This work is available under the CC BY-NC-SA 3.o IGO license (https://creativecommons.org/licenses/by-nc-sa/3.o/igo)

\section{Introduction}

Congenital anomalies (CAs), are functional or structural anomalies that can be identified prenatally, at birth, or may only be diagnosed later in life as in cases with hearing defects $(1,2)$. Many researchers have reported that the musculoskeletal system, central nervous system (CNS), gastrointestinal tract (GIT) and genitourinary system are the most frequently affected (3). The etiology of up to $60 \%$ of CAs is still unknown and multifactorial causes account for $20-25 \%$ of cases. There is a complex interaction between environmental and genetic risk factors. Around $10-13 \%$ of CAs have a well-recognized environmental cause (e.g., infections, illness or maternal drug abuse) $(2-4)$, and $12-25 \%$ of CAs have a purely genetic cause. Chromosomal anomalies are responsible for most malformations that occur due to genetic factors. The reported risk factors include consanguinity, advanced parental age, nutritional deficiency, and teratogens, such as drugs and infectious agents (5).

The importance of CAs lies not only in their contribution to neonatal and perinatal mortality, but also that they lead to disability in infants and children (6). CAs have a major impact on patients, families, healthcare systems and society (7), and they also lead to emotional upset and social stigma in parents (8).

According to the World Health Organization, there were 270000 deaths during the first 28 days of life caused by CAs worldwide in 2010 (2). According to the March of Dimes global report on birth defects, $6 \%$ occur annually with serious defects and $94 \%$ of these births occur in middle- and low-income countries $(1,2)$.

There are insufficient reports regarding the epidemiology of CAs in developing countries (9). Many different surveys since the 1960 s have tried to estimate the prevalence of CAs around the world (10), with $1 \%$ in Japan, 4.3\% in Taiwan, 2\% in England, 2-3\% in the United States of America and $3.65 \%$ in India (11). These variations may be related to regional differences in maternal risk factors, environmental exposure, and economic, ecological and ethnic factors (12). In the Middle East where consanguinity is common, the prevalence of major CAs is $2-2.5 \%$, but it can be as high as $7 \%$ from consanguineous marriage (13). The prevalence of CAs in Africa may be different from that in the developed world, due to differences in genetics and exposure to environmental risk factors. The available data on CAs in Africa underestimate their 
prevalence. This is because of under-reporting, lack of reliable medical records, minimal diagnostic capabilities and poor postnatal follow-up for full clinical examination and accurate diagnosis of CAs (14). In Egypt, only a small number of studies from university and general hospitals have demonstrated the prevalence of CAs among live and still births (15).

The main objectives of this study were to identify and report different types of CAs in neonates in the 2 major referral hospitals in Fayoum Governorate, and to correlate between types of CAs and different possible risk factors.

\section{Methods}

This was a cross-sectional hospital-based study from August 2017 to April 2018 of 1000 neonates from birth to age 28 days at the neonatal intensive care unit (NICU) and outpatient clinics of Fayoum University Hospital and Fayoum General Hospital. The sample size was calculated by Epi info 2000 software based on a worldwide prevalence of CAs of $\sim 3 \%$ of neonates (16) at $95 \%$ confidence interval and $80 \%$ study power. The sample was increased by $10 \%$ to overcome missing data.

This study was approved by the Faculty of Medicine Research Ethical Committee, Fayoum University. The researchers explained to parents of all participants the objectives of the study, as well as the examination and investigations to be done. Also, confidentiality of patient information and the right not to participate in the study were respected. Consent was obtained from the parents of all participants.

A full history was taken from the parents. We recorded rural or urban residence, maternal gravidity and parity, family history, birth defects, maternal history of abortion or stillbirth, maternal chronic illness, consanguinity, prenatal history, maternal age at conception, drug intake during pregnancy, and exposure to infection or radiation especially during the first trimester. Antenatal ultrasonography and number of visits were recorded, along with natal history, including gestational birth and mode of delivery. The newborns were examined thoroughly to look for any congenital anomaly or facial dysmorphism. Different body systems were examined, including cardiovascular, respiratory, skeletal, neurological and genitourinary systems. When indicated, karyotyping, abdominal ultrasonography, echocardiography and brain imaging were performed.

We classified the anomalies according to the European Surveillance of Congenital Anomalies (EUROCAT) coding system into major and minor anomaly groups (17): $5.8 \%$ had major anomalies and 1.6\% had minor anomalies.

Microsoft Excel 2010 was used for data entry. IBM SPSS version 21 (SPSS Inc., Chicago, IL, USA) was used for data analysis. Descriptive statistics such as frequency distribution and comparisons were used. Qualitative data were displayed in cross tabulations and comparisons of proportions were performed using Fisher's exact and $\chi^{2}$ tests. $P<0.05$ was considered statistically significant. All tests were 2-tailed.

\section{Results}

CAs were found in $74 / 1000(7.4 \%)$ neonates: $56 / 460$ in NICU (12.17\%) and 18/540 (3.33\%) in outpatient clinics. CAs were more frequently diagnosed in rural (61/74; $82.4 \%)$ compared with urban $(13 / 74 ; 17.6 \%)$ areas, which showed a significant association between residence and occurrence of CAs $(P=0.018)$ (Table 1). Forty-six $(62.1 \%)$ cases were male, $17(36.5 \%)$ were female and $1(1.4 \%)$ had ambiguous genitalia. There was a male to female ratio of 1.7:1, but the difference was not significant $(P=0.241)$. Sixty-three (85.1\%) births were full term and $11(14.9 \%)$ were preterm, but the difference was not significant $(P=0.203)$. Seventy-one $(95.9 \%)$ births were singletons and $3(4.1 \%)$ were twins, and in all cases the second twin was normal.

Regarding maternal parity, 34(45.9\%) infants were born to women of fourth gravida or more, $17(23 \%)$ were third gravida, $13(17.6 \%)$ were second gravida and $10(13.5 \%)$ were primigravida (Table 1). There was a significant association between multiparty and CAs $(P=0.001)$. Only $32(43.2 \%)$ mothers received antenatal care ( $\geq 3$ visits), and there was a significance difference between poor attendance to antenatal clinic and CAs $(P=0.001)$. Five cases $(6.8 \%$ )were prenatally diagnosed ( 3 had CNS anomalies, 1 had renal anomalies and the other had multiple CAs). Consanguinity was positive in $41(55.4 \%)$ cases with CAs, which was statistically significant $(P=0.001)$ (Table 1$)$. History of maternal systemic illness was reported in 8 cases (10.8\%) (anaemia, cardiac problem, thyrotoxicosis, hypertension and breast cancer). Thirteen (17.6\%) cases with CAs had perinatal complications as pregnancyinduced hypertension (PIH), gestational diabetes, preeclampsia, polyhydramnios, oligohydramnios, exposure to magnetic resonance imaging radiation, and multiple pregnancies. Seventeen cases (23\%) with CAs had a history of complications during previous pregnancies (birth defects, abortion and stillbirths).

Cardiovascular system anomalies were the most commonly reported $(24 / 74 ; 32.4 \%$ ) (Table 2). Among this group, the most frequent anomalies were anomalies of cardiac septa $(10 / 74 ; 13.5 \%)$. The musculoskeletal system anomalies were the second most common $(14 / 74 ; 18.9 \%)$; the most frequent anomalies were talipes equinovarus $(9 / 74 ; 12.2 \%)$. Chromosomal anomalies were the third most common (8/74; 10.8\%); the most frequent anomalies were Down's syndrome $(7 / 74 ; 9.5 \%)$. Seven $(9.5 \%)$ had CNS anomalies; the most frequent was congenital hydrocephalus $(2 / 74 ; 2.7 \%)$. Other anomalies are listed in Table 2, and $3(4.1 \%)$ had multisystem anomalies. The lowest frequency of CAs was related to the urinary system $(2 / 74 ; 2.7 \%)$. 


\begin{tabular}{|c|c|c|c|c|}
\hline \multicolumn{5}{|c|}{ Congenital anomalies } \\
\hline & With & Without & Total & $\boldsymbol{P}$ \\
\hline \multicolumn{5}{|l|}{ Consanguinity } \\
\hline Positive & $41(12 \%)$ & $300(88 \%)$ & $341(100 \%)$ & \multirow[t]{2}{*}{0.001} \\
\hline Negative & $33(5 \%)$ & $626(95 \%)$ & $659(100 \%)$ & \\
\hline \multicolumn{5}{|l|}{ Total } \\
\hline Count (\%) & $74(7.4 \%)$ & $926(92.6 \%)$ & $1000(100 \%)$ & \\
\hline \multicolumn{5}{|l|}{ Residence } \\
\hline Urban & $13(4.4 \%)$ & $283(95.6 \%)$ & $296(100 \%)$ & \multirow[t]{2}{*}{0.018} \\
\hline Rural & $61(8.7 \%)$ & $643(91.3 \%)$ & $704(100 \%)$ & \\
\hline \multicolumn{5}{|l|}{ Total } \\
\hline Count & $74(7.4 \%)$ & $926(92.6 \%)$ & & \\
\hline \multicolumn{5}{|c|}{ Order of pregnancy } \\
\hline $\mathrm{G}_{1}$ & $10(4.20 \%)$ & $230(95.80 \%)$ & 240 & \multirow[t]{4}{*}{0.001} \\
\hline $\mathrm{G}_{2}$ & $13(5.30 \%)$ & $234(94.70 \%)$ & 247 & \\
\hline $\mathrm{G}_{3}$ & $17(6.90 \%)$ & $229(93.10 \%)$ & 246 & \\
\hline $\mathrm{G}_{4}$ and more & $34(12.70 \%)$ & $233(87.30 \%)$ & 267 & \\
\hline \multicolumn{5}{|l|}{ Route of delivery } \\
\hline CS & $61(7.30 \%)$ & $769(92.70 \%)$ & 830 & \multirow[t]{2}{*}{0.893} \\
\hline NVD & $13(7.60 \%)$ & $157(92.40 \%)$ & 170 & \\
\hline \multicolumn{5}{|l|}{ Antenatal care } \\
\hline Yes & $32(5.00 \%)$ & $608(95.0 \%)$ & 640 & \multirow[t]{2}{*}{0.001} \\
\hline No & $42(11.70 \%)$ & $318(88.30 \%)$ & 360 & \\
\hline
\end{tabular}

Abbreviations: $C S=$ caesarean section; $G=$ gravida $N V D=$ normal vaginal delivery.

\section{Discussion}

We found 74 (7.4\%) CAs among 1000 neonates in Fayoum Governate, Egypt. This is high when compared with studies in other governorates in Egypt: 3.17\% in Giza (18), 2.75\% in Cairo (15), 2.06\% in Assiut (19) and 2.5\% in Zagazig (20). Regional differences in percentage of CAs from 1 area to another may be attributed to many factors, such as different methods used for detection and reporting of CAs, and differences in environmental exposure, nutritional status and habits of pregnant women in a particular locality (19). Higher rates of consanguinity in Upper Egypt may have contributed to the increase in CAs. The high percentage of CAs in our study could have been because the study was conducted in 2 major referral hospitals in Fayoum Governorate, or it may indicate the presence of environmental teratogens (e.g., pesticides) or other risk factors within the Governorate that need to be investigated.

Other countries have shown variable rates of CAs: $2.46 \%$ in Oman (21), $1.25 \%$ in Kuwait (22), $2.4 \%$ in Lebanon (16), 3.76\% in the Islamic Republic of Iran (23), 15\% in Pakistan (24), 6.2\% in Nigeria (25), 6.2\% in Barbados (26), $2.89 \%$ in the United States of America (USA) (27), 8.39\% in Nepal (28) and 6.2\% in Bangladesh (29). These differences were probably due to differences in study design (data source and length of observation) (26). The incidence of CAs can be determined by several factors such as the population, duration, location and date of the study (30). Variable rates of CAs could also be related to different social, ethnic and racial factors (31).

According to the EUROCAT criteria for CAs, minor anomalies are those that have lesser medical, functional or cosmetic consequences. In our study, we considered as minor anomalies isolated hypospadias, talipes calcaneovalgus, congenital laryngiomalacia, isolated polydactyly, congenital palato-oesophogeal incoordination, benign undescended testicles and choledocal cyst. Out of 74 CAs, 16 were grouped as minor anomalies (21.6\%) and 58 as major anomalies (78.4\%). The latter was greater than in a study in Nigeria (25), where $59.6 \%$ had major anomalies.

In the current study, cardiovascular anomalies were the most commonly reported (32.4\%) followed by musculoskeletal (18.9\%), chromosomal (10.8\%), CNS (9.5\%), GIT (6.8\%), genital (5.4\%), eye, head and neck (5.4\%), respiratory $(4.1 \%)$, multisystem (2 or more) $(4.1 \%)$, and renal and urinary $(2.7 \%)$ anomalies. In Lebanon, the most common were cardiovascular and limb anomalies (both 16.6\%) (16). In Barbados, the most common anomalies were cardiovascular (20.4\%) followed by malformations of the musculoskeletal system (15.5\%) and digestive system (13\%) (26). In the USA, the most commonly affected area were the cardiovascular (35.5\%) and genitourinary (27.7\%) systems (27). In Bangladesh, the most common anomalies 


\begin{tabular}{|c|c|c|c|c|c|}
\hline Item & Frequency & $\%$ & Item & Frequency & $\%$ \\
\hline Central nervous system & 7 & 9.5 & Eye, head and neck & 4 & 5.4 \\
\hline Congenital hydrocephalus & 2 & 2.7 & Cleft palate with cleft lip & 1 & 1.4 \\
\hline Thoracic spina bifida with hydrocephalus & 1 & 1.4 & Anophthalmos & 1 & 1.4 \\
\hline Holoprosencephaly & 1 & 1.4 & Media neck cyst & 1 & 1.4 \\
\hline Dandy-Walker syndrome & 1 & 1.4 & Dysmorphic face & 1 & 1.4 \\
\hline Agenesis of corpus callosum & 1 & 1.4 & Total & 74 & 100 \\
\hline
\end{tabular}

Anencephaly

Chromosomal

Down syndrome

Pierre Robin sequence/syndrome

Cardiovascular system

Dextrocardia with situs inversus

Endocardial cushion defect

Congenital malformations of cardiac septa

Congenital malformations of the heart, unspecified

Congenital cardiomyopathy

Pulmonary valve atresia

Tetralogy of Fallot

Respiratory system

Congenital laryngomalacia

Congenital diaphragmatic hernia

Choanal atresia

\section{Gastrointestinal system}

Congenital hypertrophic pyloric stenosis

Congenital palato-oesophageal

incoordination

Choledochal cyst

Duplication: biliary duct

Exomphalos

Renal and urinary system

Congenital posterior urethral valves

Congenital hydronephrosis

\section{Genital system}

Hypospadias, penile

Ambiguous genitalia

Undescended testicle

Musculoskeletal system

Talipes equinovarus

Polydactyly

Polysyndactyly

Talipes calcaneovalgus

Congenital deformities of hip

Multisystem (2 or more)

Dysmorphic features + nervous + renal + urinary

Cardiac + renal + musculoskeletal

Cleft palate with cleft lip + congenital cataract

involved the cardiovascular system (59.04\%), followed by club foot $(8.57 \%)$ and Down syndrome (7.61\%) (29). In Egypt, CNS anomalies were the most frequent, followed by chromosomal and genital ]anomalies (15). Similarly, in Turkey, the most common anomalies were related to the CNS, followed by cleft palate and lip and musculoskeletal disorders (32). In Iraq, the most common CAs were CNS anomalies, cleft palate and lip and musculoskeletal anomalies (33). CNS anomalies were the most common in the Islamic Republic of Iran, followed by congenital heart disease and ear/eye defects (34). In the United Republic of Tanzania, the most affected region was the CNS, followed by the musculoskeletal and GIT systems (35). In other areas in Egypt, in Assiut, the most frequently involved area was the musculoskeletal system, followed by genitourinary system and CNS (19). In Zagazig, anomalies of the musculoskeletal system were the most commonly reported, followed by the CNS and GIT (20). In conclusion, CAs of the cardiovascular and musculoskeletal systems seem to be the most commonly reported in the literature.

In the current study, the rate of CAs was higher among male $(62.1 \%)$ than female $(36.5 \%)$ neonates, which was consistent with other studies in Egypt $(15,20)$ and other countries (5,32), although the sex difference was not significant. The male preponderance for CAs is thought to be that male embryos are more vulnerable to oxidative stress (19).

In our study, $55.4 \%$ of neonates with CAs were born to consanguineous parents, which differed significantly from the number born to non-consanguineous parents. This shows that positive consanguinity is one of the risk factors for Cas. Several other studies have reported similar results $(15,20,16)$. The Arab preference for consanguinity to maintain the family property and structure, easier marital arrangements, and financial advantages will always be a risk factor for CAs.

Most of the anomalies in our study were detected in infants born to mothers aged 21-29 years. A similar maternal age range was reported in a study of CAs in India (31), whereas El Koumi et al. reported a wider maternal age range between 20 and 35 years (20). Other studies in Entebbe (Uganda), Egypt and in Ebril (Kurdistan) have found that most infants with CAs were born to mothers aged $>35$ years $(3,15,32)$, who have an increased risk of 
chromosomal aberrations (15). However, in Nepal, most of the CAs occur in mothers aged $<20$ years $(28)$.

In the current study, multiparity was significantly associated with CAs (45.9\%). Other studies in the United Republic of Tanzania and Egypt were consistent with our findings $(15,19,35)$. This is probably a consequence of higher maternal age (19) and the grand multipara is associated with higher risks of obstetric complications such as gestational diabetes, PIH, maternal anaemia and postpartum haemorrhage. In contrast, most CAs were found in primigravida women in Nepal and India $(25,28)$.

In our study, $82.4 \%$ of neonates with CAs had a maternal history of rural residence. This may be related to the higher risk of exposure to insecticides and pesticides in rural areas. It may also be related to increased consanguinity rate, which is the cultural norm in rural areas. However, in Assuit, there was no significant difference between maternal residence and CAs (19).

Most neonates in our study were full term (85.1\%) and $14.9 \%$ were preterm. Other studies in Zagazig and the USA have reported a high rate of birth defects among premature infants $(20,27)$. In the present study, $75.7 \%$ of neonates had average birth weight $2.5-4.0 \mathrm{~kg}$. Tenali et al. agree with our findings, and $57.5 \%$ of their cases in India had an average weight (30), while other studies showed an increased incidence of CAs in babies of low birth weight $(20,26,28)$.

We consider that proper antenatal care is to fulfil at least 3 antenatal visits. CAs were significantly associated with history of poor attendance at the antenatal clinic ( $<3$ visits), and $56.8 \%$ of mothers in our study had poor antenatal care. Mothers were not informed about the importance of proper nutrition and multivitamins and folic acid administration during their pregnancies, which influenced fetal cell division and growth. Our findings were consistent with other studies in Cairo (15).

In the current study, $82.4 \%$ of cases with CAs were delivered by caesarean section. However, this was not significant and agrees with other studies in Egypt and Brazil (5,15). Other studies have shown a significant association between the mode of delivery and CAs (19). This was most probably related to obstetric complications or fear of fetal distress during normal vaginal delivery directing the obstetrician to recommend caesarean section.
Maternal medical disorder was present in $10.8 \%$ of cases: anaemia (4.1\%), cardiac disease (1.4\%), thyrotoxicosis (1.4\%), hypertension (2.7\%) and breast cancer (1.4\%). Another study in Cairo reported $14 \%$ of cases with maternal medical disorders (15). Perinatal complications represented 17.6\%: $\mathrm{PIH}$ in $5.4 \%$, polyhydramnios in $1.4 \%$, oligohydramnios in $1.4 \%$, exposure to radiation in $1.4 \%$, multiple pregnancies in $4.1 \%$, gestational diabetes in $2.7 \%$ and pre-eclampsia in $1.4 \%$. A previous study in Cairo reported that $11 \%$ of cases with CAs had a history of perinatal complications (15) while Tenali et al. found perinatal complications in 50\% of cases in India (30). In our study, only 4 cases (5.4\%) of CAs were diagnosed prenatally, indicating poor prenatal care among the population of Fayoum. Twenty-three percent of the mothers experienced complications during their previous pregnancies and $14.9 \%$ had a history of spontaneous abortion. A previous study of CAs in Egypt reported about $50 \%$ of mothers had complications during their previous pregnancies (15).

Our study had some limitations. This was a hospitalbased study that may not reflect the overall situation with CAs in the wider community. To obtain a better picture, a community-based study should be conducted. We only targeted structural malformations, , functional anomalies were not included. Our study included only live births and stillbirths and pregnancy terminations were not included.

\section{Conclusion}

Cardiovascular, musculoskeletal and chromosomal anomalies were the most common type of CAs reported in the current study. Other anomalies involved the CNS, GIT, genital system, eyes, head and neck, respiratory system, or 2 or more systems. The least-frequent were renal and urinary anomalies. CAs were associated with risk factors such as consanguinity, poor attendance at the antenatal clinic, multiparity and rural residence. Other risk factors such as drug exposure, abnormal outcome of previous pregnancies and maternal illness were also reported. Unfortunately, poor antenatal care and lack of proper prenatal diagnosis were documented. Knowledge of the incidence and pattern of CAs is important to plan for proper preventive strategies at different levels by healthcare providers.

\section{Acknowledgement}

We would like to acknowledge all patients and their parents for their cooperation and participation in this study.

Funding: None.

Competing interests: None declared. 


\section{Anomalies congénitales chez les nouveau-nés dans le gouvernorat de Fayoum, Égypte}

\section{Résumé}

Contexte : L'incidence mondiale des anomalies congénitales est comprise entre 3 et $7 \%$ selon les estimations, mais les chiffres réels varient considérablement selon les pays. Les malformations congénitales sont les premières causes de mortalité infantile, soit environ $25 \%$ de l'ensemble des décès néonatals.

Objectifs: L'étude vise à déterminer la prévalence des anomalies congénitales chez les nouveau-nés dans le gouvernorat de Fayoum. Elle tend également à classifier les malformations et à clarifier l'association entre les anomalies congénitales et les différents facteurs de risque possibles.

Méthodes: Une étude transversale a été menée sur 1000 nourrissons dans l'unité de soins intensifs néonatals et les services de consultations externes de l'hôpital universitaire de Fayoum et de l'hôpital général de Fayoum entre août 2017 et avril 2018. Les antécédents détaillés ont été collectés, un examen clinique et des enquêtes pertinentes ont été réalisés.

Résultats: La prévalence des anomalies congénitales était de 7,4\%. Les malformations majeures représentaient $78,4 \%$ de toutes les anomalies et les malformations mineures constituaient $21,6 \%$. Les anomalies congénitales les plus fréquentes concernaient le système cardio-vasculaire (32,4 \%), suivi des anomalies musculosquelettiques (18,9\%), des anomalies chromosomiques (10,8 \%), des anomalies du système nerveux central (9,5\%), des voies gastro-intestinales (6,8 \%), de l'appareil génital (5,4\%), des yeux, de la tête et du cou (5,4\%), du système respiratoire $(4,1 \%)$, des systèmes multiples (deux ou plus) $(4,1 \%)$ et des systèmes rénal et urinaire $(2,7 \%)$. Sur l'ensemble des cas, 82,4\% venaient des zones rurales, 62,1\% étaient des hommes, 36,5\% des femmes et 1,4\% étaient ambigus ; 85,1 \% des nouveau-nés souffrant de malformations étaient nés à terme.

Conclusion: Les anomalies cardiovasculaires, musculosquelettiques et chromosomiques étaient les anomalies congénitales les plus fréquentes dans notre étude. La consanguinité positive, la faible fréquentation des cliniques prénatales, la résidence rurale et la multiparité étaient les facteurs de risque les plus fréquemment associés aux anomalies congénitales.

$$
\begin{aligned}
& \text { التشوهات الخلقية لدى حديثي الولادة في محافظة الفيوم، مصر } \\
& \text { هبة العوضي، القاسم الجميل، تامر رجب، ناصر حسن } \\
& \text { الخالاصة }
\end{aligned}
$$

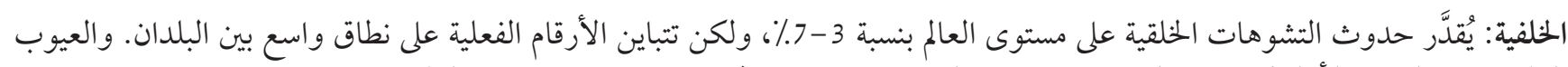

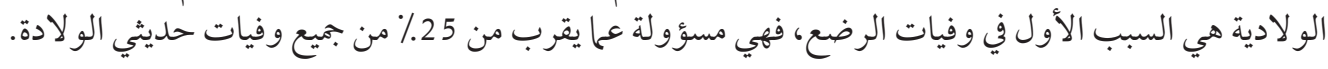

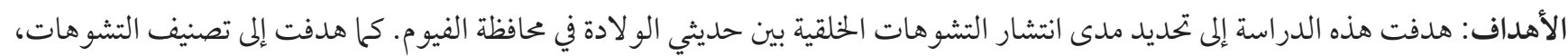

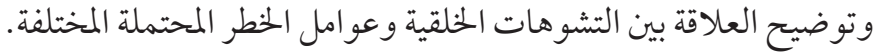

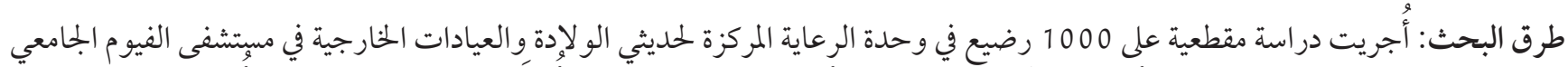

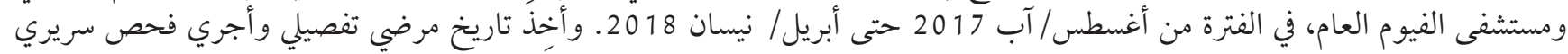

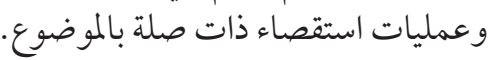

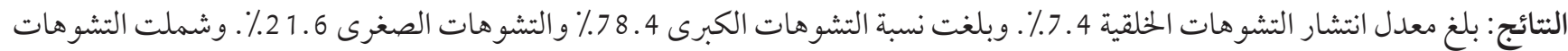

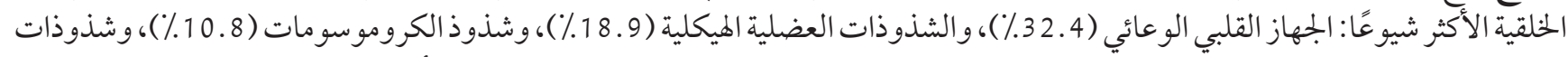

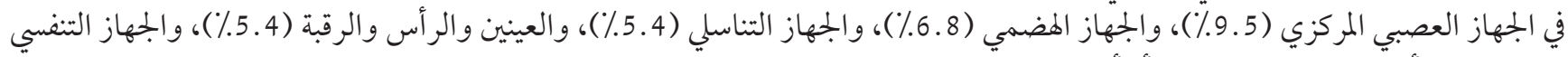

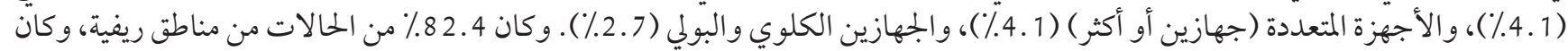

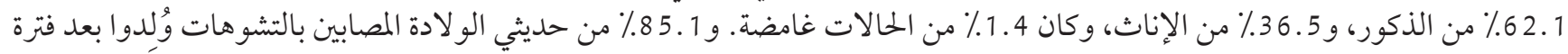

$$
\begin{aligned}
& \text { حمل مكتملة. } \\
& \text { الاستنتاج: كانت الشذوذات في القلب والأوعية الدموية والعضلات الهيكلية والكروموسو ماتوات أكثر أنواع التشوهات الخلقية شيوعًا في دراستنا. }
\end{aligned}
$$

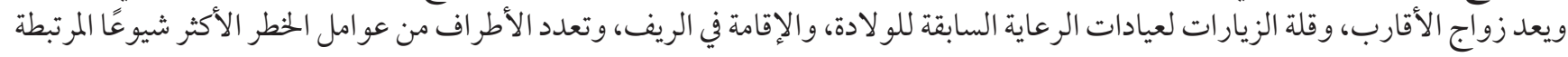

$$
\begin{aligned}
& \text { بالتشوهات الخلقية. }
\end{aligned}
$$




\section{References}

1. Congenital anomalies [website]. Geneva: World Health Organization; 2020 (http://www.who.int/mediacentre/factsheets/fs370/ en/, accessed 29 March 2021).

2. Congenital anomalies (birth defects) [website]. National Health Portal of India; 2016 (https://www.nhp.gov.in/disease/gynaecology-and-obstetrics/congenital-anomalies-birth-defects, accessed 29 March 2021).

3. Ndibazza J, Lule S, Nampijja M, Mpairwe H, Oduru G, Kiggundu M, et al. A description of congenital anomalies among infants in Entebbe, Uganda. Birth Defects Res A Clin Mol Teratol. 2011 Sep;91(9):857-61. https://doi.org/10.1002/bdra.20838 PMID:21770020

4. Dolk H, Vrijheid M. The impact of environmental pollution on congenital anomalies. Br Med Bull. 2003;68(1):25-45. https://doi. org/10.1093/bmb/ldg024 PMID:14757708

5. Oliveira CIF, Richieri-Costa A, Carvalho Ferrarese VC, Móz Vaz DC, Fett-Conte AC. Birth defects in newborns and stillborns: an example of the Brazilian reality. BMC Res Notes. 2011;4:343. https://doi.org/10.1186/1756-0500-4-343

6. Ajao AE, Adeoye IA. Prevalence, risk factors and outcome of congenital anomalies among neonatal admissions in OGBOMOSO, Nigeria. BMC Pediatr. 2019;19:88. https://doi.org/10.1186/s12887-019-1471-1

7. Kumbhar S, Lele PR. The incidence of congenital malformations at birth and mid-trimester abortions and possible etiological factors in Pune camp, Maharashtra, India. Int J Res Med Sci. 2016;44(66):1910-4. https://doi.org/10.18203/2320-6012. ijrms20161732

8. Prashar N, Gupta S, Thakur R, Sharma P, Sharma G. A study of incidence of congenital anomalies in newborn: a hospital based study. Int J Res Med Sci. 2016;4(6):2050-3. https://doi.org/10.18203/2320-6012.ijrms20161758

9. Thong MK, Ho JJ, Khatijah NN. A population-based study of birth defects in Malaysia. Ann Hum Biol. 2005 Mar-Apr;32(2):180-7. https://doi.org/10.1080/03014460500075332 PMID:16096215

10. Padmanabhan R, Venkatasubramanian R, Heber A. Prevalence and pattern of congenital malformations among neonates in a medical college hospital - a retrospective study. Int J Sci Stud. 2019;6(12):28-31.

11. Padma S, Ramakrishna D, Jijiya P, Ramana P. Pattern of distribution of congenital anomalies in stillborn: a hospital based prospective study. J Neonatol. 2011 Jan-Mar;25(1):49. https://doi.org/10.1177/0973217920110109

12. Barišić I, EUROCAT Working Group. EUROCAT - epidemiological surveillance of congenital anomalies in Europe. Slovenian Med J. 2018;78:175-9. https://vestnik.szd.si/index.php/ZdravVest/article/view/2760

13. Kanaan Z, Mahfouz R, Tamim H. The prevalence of consanguineous marriages in an underserved area in Lebanon and its association with congenital anomalies. Genet Test. 2008 Sep;12(3):367-72. https://doi.org/10.1089/gte.2007.0093.

14. Ndibazza J, Lule S, Nampijja M, Mpairwe H, Oduru G, Kiggundu M, et al. Brief report: a description of congenital anomalies among infants in Entebbe, Uganda. Clin Mol

Teratol. 2011;91:857-61.

15. Shawky RM, Sadik DI. Congenital malformations prevalent among Egyptian children and associated risk factors. Egypt J Med Hum Genet. 2011 May;12(1):69-78. https://doi.org/10.1016/j.ejmhg.2011.02.016

16. Rizk F, Salame P, Hamade A. Congenital anomalies: prevalence and risk factors. J Public Health. 2014;2(2):58-63.

17. EUROCAT guide 1.3 and reference documents. Instructions for the registration and srveillance of congenital anomalies. Newtonabbey, UK: European Surveillance of Congenital Anomalies; 2005 (http://www.eurocat-network.eu/content/EUROCAT-Guide-1.3.pdf, accessed 29 March 2021).

18. Temtamy S. A genetic epidemiological study of malformations at birth in Egypt. East Mediterr Health J. 1998;4(2):252-9. https:// apps.who.int/iris/handle/10665/118073

19. Mohammed YA, Shawky RM, Soliman A, Ahmed MM. Chromosomal study in newborn infants with congenital anomalies in Assiut University hospital: cross-sectional study. Egypt J Med Hum Genet. 2011 May;12(1):79-9o. https://doi.org/10.1016/j.ejmhg.2011.02.003

20. El Koumi MA, Al Banna EA, Lebda I. Pattern of congenital anomalies in newborn: a hospital-based study. Pediatr Rep. 2013 Feb 5;5(1):e5. https://doi.org/10.4081/pr.2013.e5 PMID:23667734

21. Sawardekar KP. Profile of major congenital malformations at Nizwa Hospital, Oman: 10-year review. J Paediatr Child health. 2005 Jul;41(7):323-30. https://doi.org/10.1111/j.1440-1754.2005.00625.x PMID:16014135

22. Madi S, Al Naggar R, Al Awadi S, Bastaki L. Profile of major congenital malformations in neonates in Al-Jahra region of Kuwait. East Mediterr Health J. 2005;11(4):700-6. https://apps.who.int/iris/handle/10665/116997

23. Tayebi N, Yazdani K, Naghshin N. The prevalence of congenital malformations and its correlation with consanguineous marriages. Oman Med J. 2010 Jan;25(1):37-40. https://doi.org/10.5001/omj.2010.9 PMID:22125696

24. Rafi M, Iqbal Z, Saleem M, Waseem M, Anwar J, Saleem M. Pattern of congenital malformations and their neonatal outcome at Sheikh Zayed Medical College/Hospital Rahim Yar Khan. Pak J Med Health Sci. 2011 Jan-Mar;5(1):93-7.

25. Akinmoladun J, Ogbole G, Oluwasola T. Pattern and outcome of prenatally diagnosed major congenital anomalies at a Nigerian tertiary hospital. Niger J Clin Pract. 2018 May;21(5):560-5. https://doi.org/10.4103/njcp.njcp_210_17 PMID:29735854 
26. Singh K, Krishnamurthy K, Greaves C, Kandamaran L, Nielsen A L, Kumar A. Major congenital malformations in Barbados: the prevalence, the pattern, and the resulting morbidity and mortality. ISRN Obstet Gynecol. 2014 Apr 6;2014:651783. https://doi. org/10.1155/2014/651783. PMID:25006483

27. Egbe A, Uppu S, Lee S, Stroustrup A, Ho D, Srivastava S. Congenital malformations in the newborn population: a population study and analysis of the effect of sex and prematurity. Pediatr Neonatol. 2015 Feb;56(1):25-30. https://doi.org/10.1016/j.pedneo.2014.03.010 PMID:25267275

28. Bastola R, Gurung R, Bastola B, S Bastola S, Bastola L. Pattern and prevalence of congenital birth defect among neonates admitted to special newborn care unit (SNCU) Of Pokhara Academy of Health Science (PAHS), Nepal. J Biol Med Res. 2017;1(1):1-5. http://www.imedpub.com/journal-biology-medical-research/

29. Ahmed W, Dey D, Farid R. Prevalence and pattern of congenital anomalies and its outcome at Chattagram Maa-O-Shishu General Hospital. Chatt Maa Shi Hosp Med Coll J. 2017 Jan;16(1):22-5.

30. Tenali AS, Kamalakannan SK, Jayaraman KK. Spectrum of congenital anomalies of neonates in a tertiary care hospital in Southern India. Int J Contemp Pediatr. 2018;5(2):314-9. https://doi.org/10.18203/2349-3291.ijcp20180030

31. Patel KG, Chaudhary C. Study of congenital malformations in newborns: a hospital based prospective study. Int J Contemp Pediatr. 2017;4(4):1409-13. https://doi.org/10.18203/2349-3291.ijcp20172676

32. Tomatir AG, Demirhan H, Sorkun HC, Koksal A, Ozerdem F, Cilengir N. Major congenital anomalies: a five-year retrospective regional study in Turkey. Genet Mol Res. 2009 Jan 13;8(1):19-27. https://doi.org/10.4238/vol8-1gmr506 PMID:19224463

33. Othman GO. The prevalence and types of congenital anomalies in newborns in Erbil. Med J Islamic World Acad Sci. 2013;21(1):31--4.

34. Abdolahi HM, Maher MHK, Afsharnia F, Dastgiri S. Prevalence of congenital anomalies: a community-based study in the northwest of Iran. ISRN Pediatr. 2014 Mar 26;2014:5. https://doi.org/10.1155/2014/920940 PMID:24995131

35. Mashuda F, Zuechner A, Chalya PL, Kidenya BR, Manyama M. Pattern and factors associated with congenital anomalies among young infants admitted at Bugando medical centre, Mwanza, Tanzania. BMC Res Notes. 2014 Mar 29;7:195. https://doi. org/10.1186/1756-0500-7-195 PMID:24679067 